1 - ORIGINAL ARTICLE

WOUND HEALING

\title{
The effects of photobiomodulation therapy on Staphylococcus aureus infected surgical wounds in diabetic rats. A microbiological, histopathological, and biomechanical study ${ }^{1}$
}

\author{
Reza Ranjbar', Mohammad Ashrafzadeh Takhtfooladi ${ }^{I}$ \\ DOI: http://dx.doi.org/10.1590/S0102-865020160080000001 \\ ${ }^{I}$ Full professor, Molecular Biology Research Center, Baqiyatallah University of Medical Sciences, Tehran, Iran. Design and supervised all phases of \\ the study. \\ IIPhD, Young Researchers and Elites Club, Science and Research Branch, Islamic Azad University, Tehran, Iran. Conception and design of the study; \\ acquisition, analysis and interpretation of data; statistical analysis; manuscript writing.
}

\begin{abstract}
PURPOSE: To evaluate the effects of photobiomodulation therapy (PBMT) at $685 \mathrm{~nm}$ on diabetic wound healing in rats suffering from bacterial infection induced by Staphylococcus aureus (S. aureus).

METHODS: Thirty streptozotocin-induced diabetic rats were allocated into two groups: control and PBMT. A 4-cm full-thickness linear-incision was made on the dorsal midline and was contaminated with $S$. aureus. The wounds in the PBMT group were irradiated daily for 5 consecutive days, starting 3 days after the induction and always in the mornings.

RESULTS: The result revealed that PBMT resulted in a significant decrease in S. aureus CFU in the PBMT group in comparison to the control group $(P<0.05)$. The length of wounds, in the 2nd and 3rd weeks, in the PBMT group were significantly shorter compared to the control group $(P<0.05)$. PBMT caused a significant increase in the histological parameters in comparison to the control group $(P<0.05)$. Moreover, PBMT significantly increased the breaking strength of the surgical scars produced in the skin of the PBMT group when compared to the control group $(P<0.05)$.
\end{abstract}

CONCLUSION: Photobiomodulation therapy may be useful in the management of wound infection through a significant bacterial growth inhibition and an acceleration of wound healing process.

Key words: Staphylococcus aureus. Wound Healing. Low-Level Light Therapy. Rats. 


\section{Introduction}

The healing process of wounds has attracted the attention of researchers since the beginning of its identification, especially with regard to the factors that delay or prevent it. The most important repair failures in skin wounds are those that occur in the diabetes mellitus (DM) or infections ${ }^{1}$. DM associated with suppression of the inflammatory reaction, decreases the migration of fibroblasts, reduced angiogenesis, changes in the proliferation of endothelial cells, and fibroblasts. On the other hand, it increases the apoptosis of them while decreasing collagen production ${ }^{2}$.

Wound infections are among the most common problems in diabetic people. Infection is one factor that changes the physiological progress of the wound healing ${ }^{3,4}$. The bacteria inhibit the angiogenesis and the proteolytic enzymes that may affect the extracellular matrix, preventing the wound contraction ${ }^{5}$. Staphylococcus aureus (S. aureus), a potentially pathogenic bacterium, is a bacterium that frequently colonizes the skin. However, if there is a break in the skin from a wound, or if there is a suppression of systemic defense, then colonizing $S$. aureus can cause an infection. Infections with $S$. aureus have been a challenge for many years. The confined population and the widespread use of antibiotics have led to the development of antibiotic-resistant strains of $S$. aureus ${ }^{6}$.

Currently, photobiomodulation therapy (PBMT) has emerged as new noninvasive therapeutic modality for various pathological conditions like pain relief, musculoskeletal disorder ${ }^{7,8}$, ischemia/reperfusion ${ }^{9,10}$, nerve repair $^{11,12}$, and diabetic wound healing ${ }^{13}$. The effects of PBMT on different types of biological tissues have been documented by in vitro and in vivo studies ${ }^{9-14}$.

The antibacterial role of PBMT has been investigated, utilizing an approach known as photodynamic antimicrobial therapy or lethal photosensitization ${ }^{15}$. In this treatment, the light emitted by a PBMT activates a specific photosensitizer triggering biochemical changes capable of killing bacteria ${ }^{16,17}$. The specific photosensitizer links itself to a target microorganism and is activated by the light at a specific wavelength causing the release of reactive oxygen species. Increased levels of free radicals may cause cell death by exhausting the molecules of adenosine triphosphate and lipid peroxidation ${ }^{18,19}$. In addition to its antibacterial effects, the PBMT has also been shown to have impression on several other factors including toxin secretion by bacteria ${ }^{20}$, cytokines $^{21}$, and synthesis and remodeling of collagen and angiogenesis ${ }^{22}$ in wounds. PBMT seems promising for the treatment of diabetic wounds where healing is impaired and the treatment is further complicated by infection ${ }^{23-26}$. Therefore, the study was carried out to evaluate the bio-stimulatory effects of PBMT at $685 \mathrm{~nm}$ and 3 $\mathrm{J} / \mathrm{cm}^{2}$, by in vivo microbiological, histological, and biomechanical analysis on diabetic wound healing in rats suffering from bacterial infection induced by $S$. aureus.

\section{Methods}

The experimental procedures with the animals used in the present study were approved by the Ethics Committee of the Islamic Azad University, Faculty of Veterinary Medicine, Tehran, Iran, under the reference code 031-4/2015.

Thirty adult male Wistar rats, weighing 200-250g, were obtained from a local colony. Subjects were randomly classified into two groups i.e. the control group and the PBMT group. Each group consisted of fifteen rats, and out of these 15, five were used for breaking strength measurement, five for bacterial load determination, and five for histopathological analysis. The rats were housed in individual plastic cages bedded with soft pad and maintained at $25 \pm 2{ }^{\circ} \mathrm{C}, 50-60 \%$ humidity, and in a $12 \mathrm{~h} / 12 \mathrm{~h}$ light/ dark cycle. The animals were fed a standard pelleted rodent diet and water ad libitum.

\section{Experimental induction of diabetes in rats}

Diabetes mellitus was induced by a single injection of streptozotocin (200 mg/kg, i.p.) in the volume of $0.2 \mathrm{ml}$, to the overnight fasting rats. Streptozotocin was dissolved in normal saline. Hyperglycemia was measured by a commercial glucometer (One Touch Sure Step, Lifescan, Milpitas, CA). After 14 days, rats with blood glucose level of $>300 \mathrm{mg} / \mathrm{dL}^{27}$ were considered as diabetic models.

\section{Experimental protocol}

On the day of the experiment, all rats were weighed and anesthetized using an intramuscular injection with a combination of ketamine $50 \mathrm{mg} / \mathrm{kg}$ and xylazine $10 \mathrm{mg} / \mathrm{kg}$. The lumbar region of the rats was shaved and scrubbed with povidone-iodine. Under sterile conditions, a $4 \mathrm{~cm}$ full-thickness linear incision was made by a surgery blade on the dorsal midline. The wound area was contaminated with one aliquot of $50 \mu \mathrm{L}$ of a saline solution containing approximately $5 \times 10^{7} \mathrm{CFU} / \mathrm{mL}$ of $S$. aureus, and afterwards, the infected skin wound was closed with 4-0 nylon strands using simple separate sutures at a distance of $1 \mathrm{~cm}$ from each other. Bacteria were allowed to grow in wounds for $48 \mathrm{~h}$. 
Infection signs were observed on the 2nd post-wounding day, suggesting development of infection in the wounds. All surgical procedures were performed by a surgeon, and the animals were allowed to move freely in their individual cages.

\section{Laser irradiation}

A $685 \mathrm{~nm}$ InGaAlP $\left(15 \mathrm{~mW}, 3 \mathrm{~J} / \mathrm{cm}^{2}\right.$, spot of $0.028 \mathrm{~cm} 2$, Teralaser; DMC ${ }^{\circledR}$ São Carlos-SP, Brazil) was used in the present study. The mean power of the laser equipment was measured with a power measuring device before the study. The infected wounds were irradiated daily for five consecutive days, starting on the 3rd day post-induction, and always in the mornings. The animals were immobilized by the assistant, and the contact technique was used with perpendicular application divided into five points of the wound, for $5 \mathrm{~min}$. The control group animals underwent sham irradiation with the turned off equipment.

\section{Macroscopic analysis}

All rats were examined daily for general appearance during which they proceeded to macroscopic evaluation of the wound, and the data were recorded on separate sheets. For the macroscopic analyses, the length of the wounds was measured by one person using a caliper on the days $0,3,5,8,14$ and 21 postsurgery. The sutures were removed 14 days post operation.

\section{Euthanasia and tissue sampling}

At the end of the trial, euthanasia was performed using an overdose of anesthetic drugs, and then, skin samples were harvested.

\section{Bacteriological analysis}

For the purpose of bacterial load determination, a $1 \mathrm{~cm}$ $\times 2 \mathrm{~cm}$ sample tissue, including the wound was homogenized in $1 \mathrm{ml}$ phosphate-buffered saline (3500 rpm, $5 \mathrm{~min}$ ), and was then centrifuged $(10.000 \times \mathrm{g})$ for $10 \mathrm{~min}$. The supernatant was collected and plated on TSA agar plates. After incubation in the dark at $37^{\circ} \mathrm{C}$ for $48 \mathrm{~h}$, the number of colonies was counted. Measuring the bacterial load was done by multiplying the number of colonies with dilution factor and volume of supernatant obtained during the tissue homogenization and was presented as $\log \mathrm{CFU} / \mathrm{ml}^{28}$.

\section{Histopathological analysis}

The skin specimens for histopathological analysis were processed following the standard methods (fixed in $10 \%$ formalin for $24 \mathrm{~h}$, embedded in paraffin, cut sections of $5 \mu \mathrm{m}$ thickness, and stained by hematoxylin and eosin). The histological sections were evaluated by one pathologist who was blinded to the experiment as suggested by Gál et al. ${ }^{29}$ by the following scale: $0,1,2$, and 3 (Table 1).

TABLE 1 - Explanation of scale used in evaluation of histological sections.

\begin{tabular}{cccccccc}
\hline Scale & Epithelialization & PMNL & Macrophages & Fibroblasts & New collagen & Neo-angiogenesis \\
\hline $\mathbf{0}$ & Thickness of cut edges & Absent & Absent & Absent & Absent & Absent \\
$\mathbf{1}$ & Migration of epithelial cells & Mild & Mild & Mild & Mild & Mild \\
$\mathbf{2}$ & Bridging of the incision & Moderate & Moderate & Moderate & Moderate & Moderate \\
$\mathbf{3}$ & Complete regeneration & Marked & Marked & Marked & Marked & Marked \\
\hline
\end{tabular}

Breaking strength analysis

For the purpose of measuring the breaking strength of scars, a strip of skin, $7 \mathrm{~cm}$ long and with the same widths of wound diameter was carefully removed by a scalpel in the manner that the wound was located at the middle of the strip. Then, the segment was pulled at both ends by two clamps until being broken using a machine for biomechanical assays (Zwick/Roell, Ulm, Germany).

\section{Statistical analysis}

A Kruskal-Wallis or Student's t-test was performed to compare the two mean scores. A value of $P<0.05$ was considered the significance level.

\section{Results}

Data analysis shows that inhibition of bacterial growth was achieved by PBMT. In detail, mean bacterial numbers in PBMT group $\left(0.51 \times 10^{1} \pm 0.2 \times 10^{1} \mathrm{CFU} / \mathrm{ml}\right)$ were significantly lower $(P<0.05)$ than in the control group $\left(8.4 \times 10^{7} \pm 1.8 \times 10^{7}\right.$ $\mathrm{CFU} / \mathrm{ml})$. Figure 1 illustrates wound lengths throughout this study. The length of wounds in the PBMT group were significantly shorter compared to those of the control group $(P<0.05)$. There was no significant difference in the mean scores for the decrease in the lengths of wounds between the PBMT and the control groups 
on the $3 \mathrm{rd}, 5$ th and 8 th days. However, the differences between the two groups on the 14 th and 21 st days were significant $(P<0.05)$.

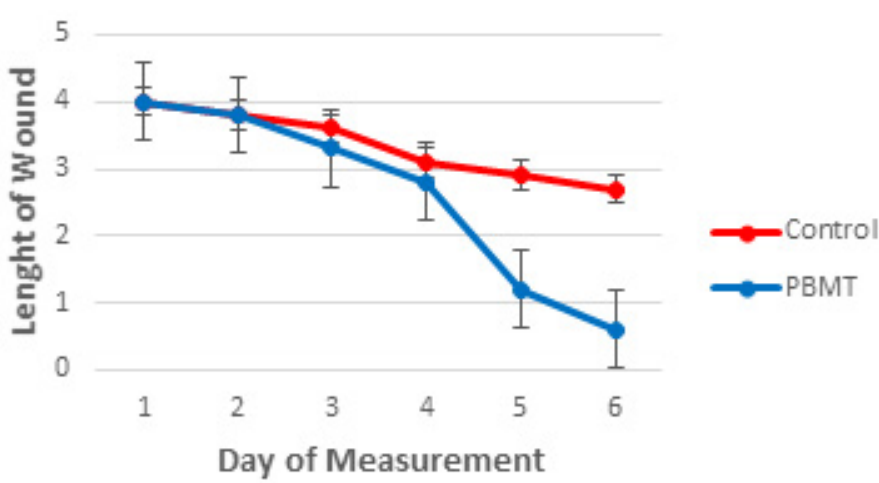

FIGURE 1 - The wound lengths (cm) in the two groups during different days.

Figure 2 demonstrates improvement in the PBMT group in macroscopic study.
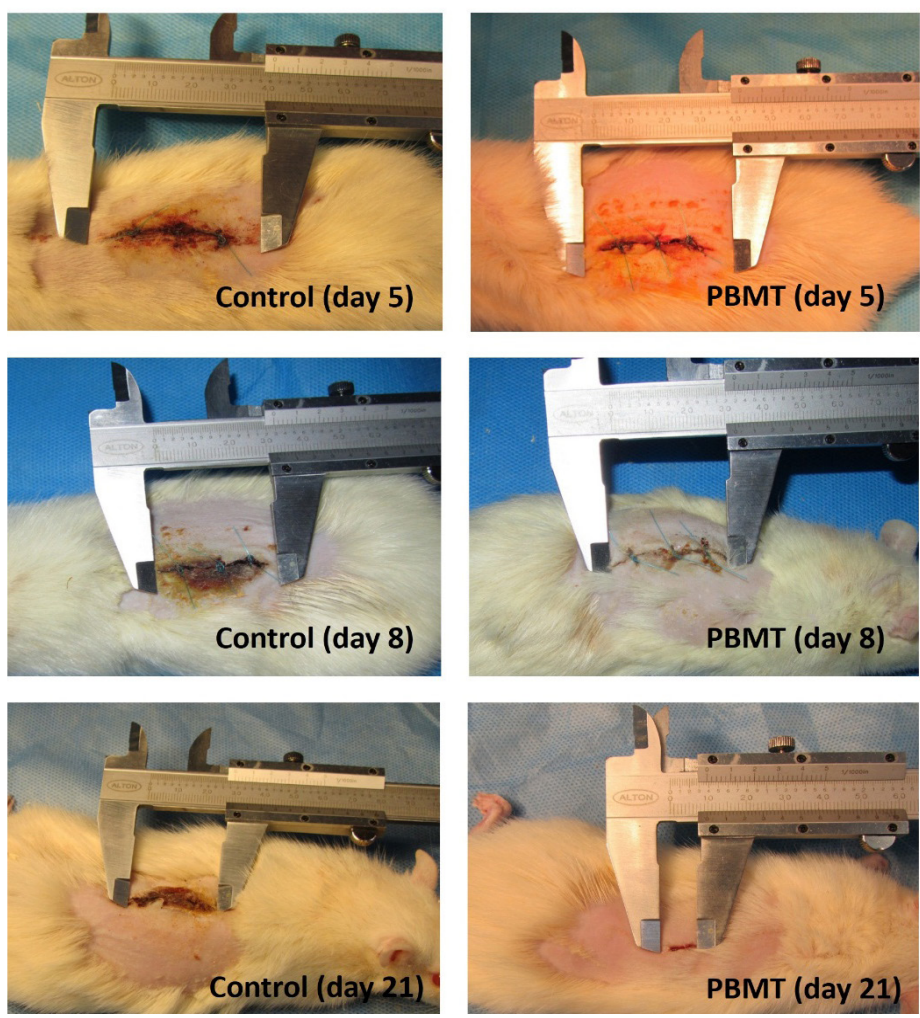

FIGURE 2 - Improvement process of wound healing in the two groups.

Histological results appear in Table 2. According to the results, PBMT caused a significant increase in both the number of macrophages and the new blood vessels $(P<0.05)$. The rats in the PBMT group exhibited significantly elevated fibroblast numbers as well as elevated collagen deposition in comparison to the control group $(P<0.05)$. The light microscopy results are shown in Figures 3 and 4.
TABLE 2 - Semi-quantitative evaluation (mean \pm standard deviation) of histological structures after photobiomodulation therapy (PBMT).

\begin{tabular}{ccccccc}
\hline Group & $\begin{array}{c}\text { Epithe- } \\
\text { lializa- } \\
\text { tion }\end{array}$ & PMNL & $\begin{array}{c}\text { Macro- } \\
\text { phages }\end{array}$ & $\begin{array}{c}\text { Fibro- } \\
\text { blasts }\end{array}$ & $\begin{array}{c}\text { New } \\
\text { colla- } \\
\text { gen }\end{array}$ & $\begin{array}{c}\text { Neo- } \\
\text { angio- } \\
\text { genesis }\end{array}$ \\
\hline PBMT & $2.2 \pm$ & $0.5 \pm$ & $0.9 \pm$ & $2.0 \pm$ & $1.9 \pm$ & $1.7 \pm$ \\
& $0.7^{*}$ & $0.4^{*}$ & $0.2^{*}$ & $0.6^{*}$ & $0.5^{*}$ & $0.4^{*}$ \\
Con- & $0.4 \pm$ & $2.1 \pm$ & $1.9 \pm$ & $0.8 \pm$ & $0.8 \pm$ & $1.0 \pm$ \\
trol & 0.5 & 0.3 & 0.7 & 0.4 & 0.4 & 0.1 \\
${ }^{*} p<0.05$ & & & & & &
\end{tabular}

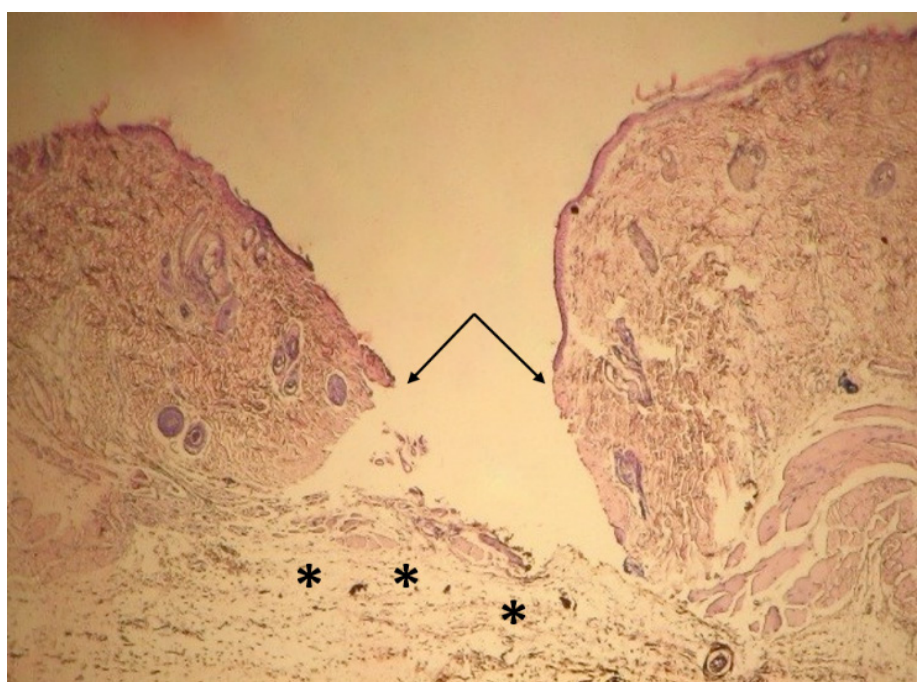

FIGURE 3 - Representative histological images of the wound (skin) area as seen by hematoxylin and eosin staining from control group on 21 day following surgery. The epithelial gap (arrows). The connective tissue of the superficial dermis is formed by a loose connective containing active fibroblasts $(*) .(\times 40)$.

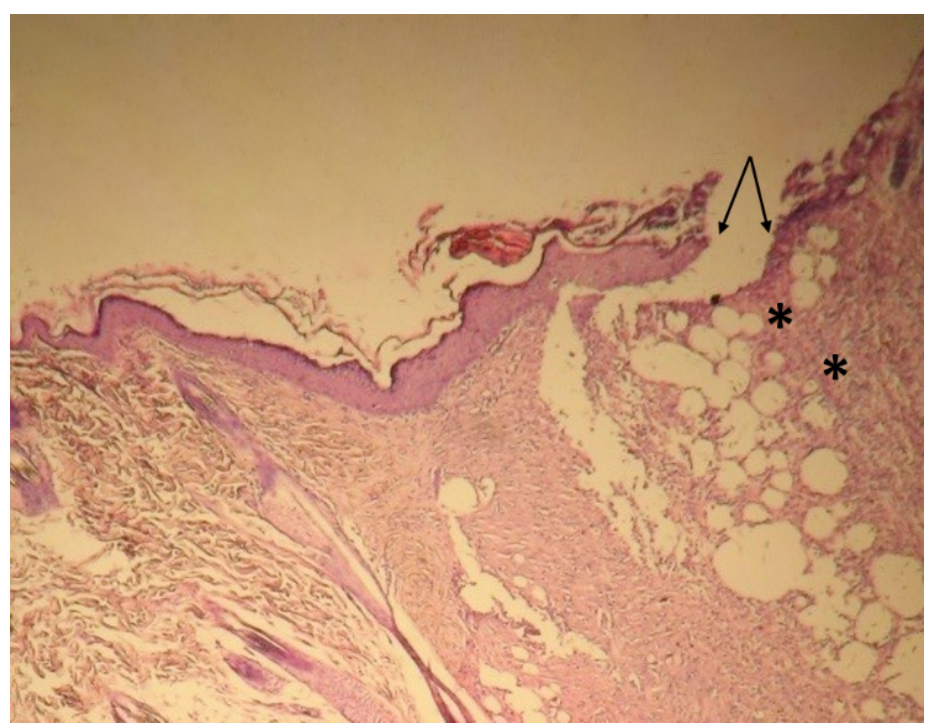

FIGURE 4 - Representative histological images of the wound (skin) area as seen by hematoxylin and eosin staining from PBMT group on 21 day following surgery. The epithelial gap in treatment group $(\times 40)$. Compare the gap with the Figure 3. 
The breaking strength of scars in the rats' skin is presented in the Figure 5. PBMT significantly increased the breaking strength of surgical scars produced in the skin of PBMT group when compared to the control group $(P<0.05)$.

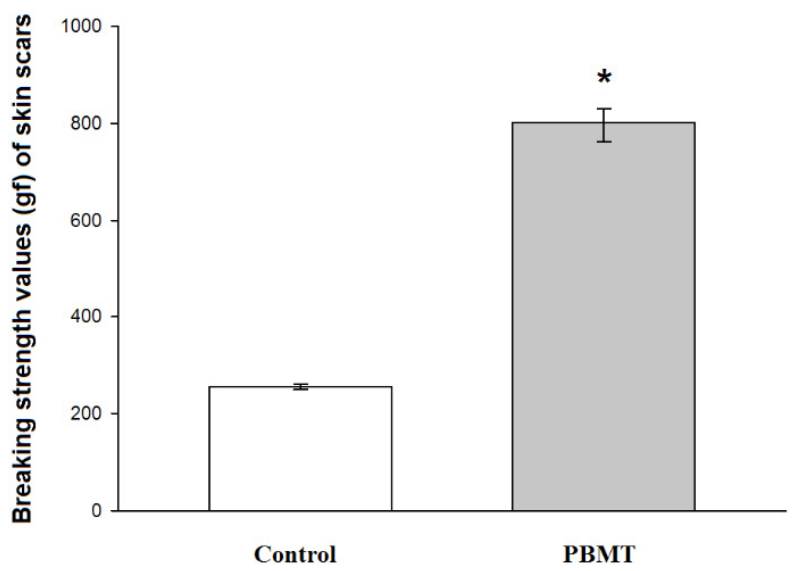

FIGURE 5 - The effect of photobiomodulation therapy (PBMT) on breaking strength at 21 days after induction of infectious wound in diabetic rat. PBMT was performed daily from 3 to 8 days after wounding. *Statistically significant difference (p0.05) in comparison with the control.

\section{Discussion}

The healing process of wounds can be partitioned into four stages (i.e. hemostasis, inflammation, proliferation, and remodeling) each of which can be affected by many factors. The highest prevalence of repair failures often occurs in the early stages. Infection is an important factor that prolongs the inflammation stage. S. aureus Infections are more frequent in diabetic patients and potentially increase their morbidity and mortality. Infection in diabetes is caused by the hyperglycemia that favors neutrophil dysfunction, antioxidant depression, angiopathies, and neuropathy ${ }^{30}$. In order to treat bacterial infections and prevent their progression, various treatment strategies such as antibiotics have been employed. However, concerns about the reduction of drug penetration in infected areas, drug resistance, and their side effects have led to the increased use of physical agents such as PBMT.

Several studies demonstrated the positive results of the use of PBMT for the eradication of microorganism. Kaya et al. ${ }^{31}$ demonstrated that the use of PBMT at $808 \mathrm{~nm}$, caused bacterial death in experimental chronic osteomyelitis induced by $S$. aureus. Other researchers investigated the effects of blue light $(470 \mathrm{~nm})$ on $S$. aureus in an in vitro study and suggested that PBMT with a low dose may be an affordable and practical alternative to other treatment types ${ }^{32}$. The findings of the present study are aligned with the previous studies which showed that the use of PBMT is clinically effective in killing bacteria. Our results showed that laser irradiation resulted in a significant decrease in $S$. aureus $\mathrm{CFU}$ in the PBMT group in comparison to the control group. PBMT has beneficial effects on morphological changes in diabetic wound healing. A previous study ${ }^{33}$ reported that PBMT enhanced wound healing in diabetic mice, as evidenced by wound closure and the histopathological evaluation of wounds of treated and untreated animals. Kana et al. $^{34}$ found that maximum enhancement of skin wound healing when utilizing a laser was reached at a daily dose of $4 \mathrm{~J} / \mathrm{cm}^{2}$. Kawalec et al. ${ }^{35}$ also witnessed the positive effect of $980 \mathrm{~nm}$ laser radiation at $18 \mathrm{~J} / \mathrm{cm}^{2}$ on wound healing in diabetic mice. In the present study, the PBMT group showed an accelerated process of inflammation and proliferation that is in agreement with previous studies ${ }^{36,37}$. Furthermore, in the current study, the PBMT wounds showed an increase in the amount of collagen fibers and a more evident remodeling of connective tissue, and this corresponded with the results of the study where the PBMT at 685 $\mathrm{nm}$ with a dose $2.5 \mathrm{~J} / \mathrm{cm}^{2}$ was utilized for skin wound treatment ${ }^{38}$.

The beneficial effects of the PBMT on tensile strength in the experimental diabetic and nondiabetic wounds have been examined. Lyons et al. ${ }^{39}$ showed a substantial improvement in skin tensile strength and a significant improvement in the total collagen content. Stadler et $a l .^{40}$, using an incisional model, showed a beneficial effect of PBMT $(830 \mathrm{~nm})$ at $5 \mathrm{~J} / \mathrm{cm}^{2}$ on the skin wound tensile strength tests in diabetic mice; they evaluated on 11th and the $23 \mathrm{rd}$ post-treatment days. This study provides preliminary data which suggest that PBMT is capable of enhancing wound tensile strength. It was observed that the control group showed significant reduction in the breaking strength of scars produced in the skin when compared to the PBMT group. According to our results, it is confirmed that the healing of diabetic wounds in the PBMT group were accelerated by PBMT, although the wounds were infected by the same bacteria as the wounds of the control group. Therefore, the authors emphasize the need for further study to evaluate the possible effects of the PBMT on infectious wounds. Hopefully this study will stimulate further research in this scope.

\section{Conclusions}

Diabetic rat showed that the use of photobiomodulation therapy may be useful in the management of wound infection through a significant bacterial growth inhibition and an acceleration of wound healing process. Moreover, interventions that shorten 
repair time could reduce patient suffering, increase life quality, and reduce healthcare costs.

\section{References}

1. Carvalho PT, Mazzer N, dos Reis FA, Belchior AC, Silva IS Analysis of the influence of low-power HeNe laser on the healing of skin wounds in diabetic and non-diabetic rats. Acta Cir Bras. 2006 May-Jun;21(3):177-83. PMID: 16751932.

2. Ebaid H, Salem A, Sayed A, Metwalli A. Whey protein enhances normal inflammatory responses during cutaneous wound healing in diabetic rats. Lipids Health Dis. 2011 Dec;10:235-45. PMID: 22168406

3. Pishori T, Siddiqui AR, Ahmed M. Surgical wound infection surveillance in general surgery procedures at a teaching hospital in Pakistan. Am J Infect Control. 2003 Aug;31:296-301. PMID: 12888766 .

4. Narong MN, Thongpiyapoom S, Thaikul N, Jamulitrat S, Kasatpibal $\mathrm{N}$. Surgical site infection in patients undergoing major operations in a university hospital: Using standardized infection ratio as a benchmarking tool. Am J Infect Control. 2003 Aug;31:274-9. PMID: 12888762.

5. Perry AW, Sutkin HS, Gottlieb LD. Skin graft survival. The bacterial answer. Ann Plast Surg. 1989 Jun;22:479-83. PMID: 2665611.

6. Plata K, Rosato AE, Wegrzyn G. Staphylococcus aureus as an infectious agent: overview of biochemistry and molecular genetics of its pathogenicity. Acta Biochim Pol. 2009;56:597-612. PMID: 20011685.

7. Yaakobi T, Maltz L, Oron U. Promotion of bone repair in the cortical bone of the tibia in rats by low energy laser $(\mathrm{He}-\mathrm{Ne})$ irradiation. Calcif Tissue Int. 1996 Oct;59:297-300. PMID: 8781055.

8. Allahverdi A, Sharifi D, Takhtfooladi MA, Hesaraki S, Khansari M, Dorbeh SS. Evaluation of low-level laser therapy, platelet-rich plasma, and their combination on the healing of Achilles tendon in rabbits. Lasers Med Sci. 2015 May;30(4):1305-13. PMID: 25759233

9. Takhtfooladi MA, Takhtfooladi HA, Khansari M. The effects of low-intensity laser therapy on hepatic ischemia-reperfusion injury in a rat model. Lasers Med Sci. 2014 Nov;29(6):1887-93. PMID 24906482.

10. Ashrafzadeh Takhtfooladi M, Ashrafzadeh Takhtfooladi H, Sedaghatfar H, Shabani S. Effect of low-level laser therapy on lung injury induced by hindlimb ischemia/reperfusion in rats. Lasers Med Sci. 2015 Aug;30(6):1757-62. PMID: 26155904.

11. Takhtfooladi MA, Jahanbakhsh F, Takhtfooladi HA, Yousefi K, Allahverdi A. Effect of low-level laser therapy $(685 \mathrm{~nm}, 3 \mathrm{~J} / \mathrm{cm} 2)$ on functional recovery of the sciatic nerve in rats following crushing lesion. Lasers Med Sci. 2015 Apr;30(3):1047-52. PMID: 25595127.

12. Takhtfooladi MA, Sharifi D. A comparative study of red and blue light-emitting diodes and low-level laser in regeneration of the transected sciatic nerve after an end to end neurorrhaphy in rabbits. Lasers Med Sci. 2015 Dec;30(9):2319-24. PMID: 26415928.

13. Schindl A, Schindl M, Schon H, Knobler R, Havelec L, Schindl L. Low-intensity laser irradiation improves skin circulation in patients with diabetic microangiopathy. Diabetes Care. 1998 Apr;21:580-4. PMID: 9571346.

14. Mester E, Mester AF, Mester A. The biomedical effects of laser application. Lasers Surg Med. 1985;5:31-9. PMID: 3982191.

15. Feitosa MC, de Carvalho AF, Feitosa VC, Coelho IM, de Oliveira RA, Arisawa EÂ. Effects of the Low-Level Laser Therapy (LLLT) in the process of healing diabetic foot ulcers. Acta Cir Bras. 2015 Dec;30(12):852-7. PMID: 26735058.
16. Stringer GJ. Lethal laser photosensitization of Streptococcus mutans absorbed into dentine slices. In: International Congress on Lasers in Dentistry, No. 6, Maui, Hawaii. Proceedings of the International Society for Lasers in Dentistry, Utah, 1998; p.66-7.

17. Gois MM, Kurachi C, Santana EJB, Mima EGO, Spolidório DMP, Pelino JEP, Bagnato VS. Susceptibility of Staphylococcus aureus to porphyrin-mediated photodynamic antimicrobial chemotherapy: an in vitro study. Lasers Med Sci. 2010;25(3):391-5. PMID: 19585079.

18. Lin J, Bi LJ, Zhang ZG, Fu YM, Dong TT. Toluidine blue mediated photodynamic therapy of oral wound infections in rats. Lasers Med Sci. 2010;25(2):233-8. PMID: 19579005.

19. dos Reis JA Jr, de Carvalho FB, Trindade RF, de Assis PN, de Almeida PF, Pinheiro AL. A new preclinical approach for treating chronic osteomyelitis induced by Staphylococcus aureus: in vitro and in vivo study on photodynamic antimicrobial therapy (PAmT). Lasers Med Sci. 2014;29(2):789-95. PMID: 23979801.

20. Sharma M, Bansal H, Gupta PK. Virulence of Pseudomonas aeruginosa cells surviving photodynamic treatment with toluidine blue. Curr Microbiol. 2005;50:277-80. PMID: 15886909.

21. Sahu K, Sharma M, Bansal H, Dube A, Gupta PK. Topical photodynamic treatment with poly-L-lysine-chlorin $\mathrm{p} 6$ conjugate improves wound healing by reducing hyperinflammatory response in Pseudomonas aeruginosa infected wounds of mice. Lasers Med Sci. 2013 Feb;28:465-71. PMID: 22454129.

22. Sahu K, Sharma M, Sharma P, Verma Y, Rao KD, Bansal H, Dube A, Gupta PK. Effect of poly-L-lysine-chlorin p6-mediated antimicrobial photodynamic treatment on collagen restoration in bacteria-infected wounds. Photomed Laser Surg. 2014;32:23-9.

23. Sahu K, Sharma M, Dube A, Gupta PK. Topical antimicrobial photodynamic therapy improves angiogenesis in wounds of diabetic mice. Lasers Med Sci. 2015 Sep;30(7):1923-9. PMID: 26160556.

24. Morley S, Griffiths J, Philips G, Moseley H, O'Grady C, Mellish K, Lankester CL, Faris B, Young RJ, Brown SB, Rhodes LE. Phase IIa randomized, placebo-controlled study of antimicrobial photodynamic therapy in bacterially colonized, chronic leg ulcers and diabetic foot ulcers: a new approach to antimicrobial therapy. Br J Dermatol. 2013;168:617-24. doi: 10.1111/bjd.12098.

25. Tardivo JP, Adami F, Correa JA, PinhalMA, BaptistaMS. A clinical trial testing the efficacy of PDT in preventing amputation in diabetic patients. Photodiagnosis Photodyn Ther. 2014;11(3):342-50. doi: 10.1016/j.pdpdt.2014.04.007.

26. Mannucci E, Genovese S, Monami M, Navalesi G, Dotta F, Anichini R, Romagnoli F, Gensini G. Photodynamic topical antimicrobial therapy for infected footulcers in patients with diabetes: a randomized, double-blind, placebo-controlled study - the D.A.N.T.E (Diabetic ulcer Antimicrobial New Topical Treatment Evaluation) study. Acta Diabetol. 2014;51:435-40. PMID: 24352342.

27. Lim J, Sanders RA, Snyder AC, Eells JT, Henshel DS, Watkins JB 3rd. Effects of low-level light therapy on streptozotocin-induced diabetic kidney. J Photochem Photobiol B. 2010 May 3;99(2):10510. PMID: 20356759.

28. Zhao G, Usui ML, Underwood RA, Singh PK, James GA, Stewart PS, Fleckman P, Olerud JE. Time course study of delayed wound healing in a biofilm-challenged diabetic mouse model. Wound Repair Regen. 2012 May-Jun;20:342-52. PMID: 22564229.

29. Gál P, Vidinský B, Toporcer T, Mokrý M, Mozes S, Longauer F, Sabo J. Histological assessment of the effect of laser irradiation on skin wound healing in rats. Photomed Laser Surg. 2006 Aug;24(4):480 8. PMID: 16942428.

30. Siddiqui AR, Bernstein JM. Chronic wound infection: facts and controversies. Clin Dermatol. 2010 Sep-Oct;28(5):519-26. PMID: 20797512.

31. Kaya GS, Kaya M, Gürsan N, Kireççi E, Güngörmüş M, Balta H. The use of 808-nm light therapy to treat experimental chronic 
osteomyelitis induced in rats by methicillin-resistant Staphylococcus aureus. Photomed Laser Surg. 2011 Jun;29(6):405-12. PMID: 21219239.

32. Enwemeka CS, Williams D, Enwemeka SK, Hollosi S, Yens D. Blue 470-nm light kills methicillin resistant Staphylococcus aureus (MRSA) in vitro. Photomed Laser Surg. 2009 Apr;27(2):221-6. PMID: 19196103.

33. Yu W, Naim JO, Lanzafame RJ. Effects of photostimulation on wound healing in diabetic mice. Lasers Surg Med. 1997;20:56-63. PMID: 9041509.

34. Kana JS, Hutschenreiter G, Haina D, Waidelich W. Effect of lowpower density laser radiation on healing of open skin wounds in rats. Arch Surg. 1981;116(3):293-6. PMID: 7469766.

35. Kawalec JS, Hetherington VJ, Pfennigwerth TC, Dockery DS, Dolce M. Effect of a diode laser on wound healing by using diabetic and nondiabetic mice. J Foot Ankle Surg. 2004 Jul-Aug;43:214-20. PMID: 15284809.

36. Medrado AR, Pugliese LS, Reis SR, Andrade ZA. Influence of low-level laser therapy on wound healing and its biological action upon myofibroblasts. Lasers Surg Med. 2003;32:239-44. PMID: 12605432 .

37. Gál P, Kilík R, S`paková T, Pataky Š, Sabo J, Pomfy M, Longauer F, Hudak R. He-Ne laser irradiation accelerates inflammatory phase and epithelization of skin wound healing in rats. Biol Bratislava. 2005;60:691-6.

38. Silva JCE, Lacava ZGM, Kuckelhaus S, Silva LP, Neto LF, Sauro EE, Tedesco AC. Evaluation of the use of low-level laser and photosensitizer drugs in healing. Lasers Surg Med. 2004;34:451-7. PMID: 15216540.

39. Lyons RF, Abergel RP, White RA, Dwyer RM, Costel JC, Uitto J. Biostimulation of wound healing by a helium-neon laser. Ann Plast Surg. 1987 Jan;18(1):47-50. PMID: 3827131.

40. Stadler I, Lanzafame R, Evans R, Narayan V, Dailey B, Buehner N, Naim JO. 830-nm irradiation increases the wound tensile strength in a diabetic murine model. Lasers Surg Med. 2001;28:220-6. PMID: 11295756 .

\section{Correspondence:}

Mohammad Ashrafzadeh Takhtfooladi

Young Researchers and Elites Club

Science and Research Branch

Islamic Azad University, Tehran, Iran

Phone: +989121590428

Fax: +982144629353

dr_ashrafzadeh@yahoo.com

Received: Apr 18, 2016

Review: Jun 20, 2016

Accepted: July 21, 2016

Conflict of interest: none

Financial source: none

${ }^{1}$ Research performed at Molecular Biology Research Center, Baqiyatallah University of Medical Sciences, Tehran, Iran. 